\title{
Assessment of Body Mass Index (BMI) among members of staff of Kenya Medical Training College Nakuru
}

\author{
Paul Chandoo Musango ${ }^{1,}$ Daniel K. Kimwetich ${ }^{1}$, Pauline Wambeti Muriithi $^{1}$ and David Nzioka \\ Mutisya $^{2}$ \\ ${ }^{1}$ Management University of Africa, Kenya \\ ${ }^{2}$ Moi University \\ Kenya
}

\begin{abstract}
Background: The harmful effects of overweight and underweight have widely been underestimated worldwide. Body Mass Index (BMI) is a useful indicator to measure if one is underweight, overweight or obese. Setting: The research was conducted at KMTC Nakuru. All members of staff in the college were included in the study. The departments included in the study were Clinical Medicine, Nursing, Pharmacy, Laboratory Science, Environmental Science and physiotherapy. A total of eighty-nine (89) members of staff were studied: Fifteen (15) teaching staff and seventy-four (74) non-teaching staff. Objectives: To determine the BMI of staff members at KMTC Nakuru. Design: The study adopted a descriptive cross-sectional design. Justification: In Kenya and Africa in general, there is current updated data on the prevalence of overweight and obesity. This is particularly so since priority has always been on undernutrition (Mendez et al., 2005). There has been immense focus primarily on under-nutrition and food insecurity in most African countries since these are more prevalent. As a result, trends in overweight and obesity have often been overlooked in most countries. Data analysis: Scientific calculator was used to generating graphs and tables for data analysis. Findings: Teaching staff: From the results, $13 \%$ of the teaching staff had normal BMI, $60 \%$ were overweight and $27 \%$ had class I obesity. Non-teaching staff: From the results, 3\% were underweight, 39\% had normal BMI, 31\% were overweight, $19 \%$ had class I obesity, $5 \%$ had class II obesity and $3 \%$ had class III obesity. Conclusion: $60 \%$ of the teaching staff was overweight and $27 \%$ of the teaching staff was obese while $31 \%$ of the non-teaching staff was overweight and $27 \%$ were obese.
\end{abstract}

Key Words: Overweight, Obesity, BMI, Prevalence, NCDs, Teaching Staff, Non-Teaching Staff.

\subsection{INTRODUCTION}

This paper presents an outline of the prevalence of obesity and overweight and the associated dangers. It also presents the background and purpose of the study, study methodology as well as findings, conclusions and recommendations are also provided.

\subsection{Background and Aim of the Study}

Raised BMI poses major risk factor for non-communicable diseases (NCDs) (Mohammad, Rahman, Rahman, Bhuiyan, Karim, \& Chowdhury, 2016). It has been proven to be responsible for musculoskeletal disorders, cardiovascular diseases, diabetes and some cancers among others. As a result, a positive relationship between obesity and reduced life expectancy has been reported (Haslam, et al, 2005). In Kenya, as is the case with many low and middle-income countries, is now facing an upsurge of these diseases. This confounds the problem for a country that is already burdened with communicable diseases. Global statistics shows high prevalence of obesity. In 2014, over 600 million adults were obese (about 13\% of the world's population). At the same time, 1.9 billion adults were overweight (WHO, 2015). 
In the UK, evidence shows that in 2014, 61.7\% of adults were overweight or obese. Within a year (May 2015), the prevalence of overweight and obesity rose to $74 \%$ for men and $64 \%$ for women. The situation is worse in the United States of America where more than two-thirds of the adult population was overweight or obese in 2014 (Ogden et al., 2014). Studies such as those of Loscalzo (2008) and World Health Organization (2015) predicted that overweight and obesity are likely to overtake previously known health concerns such as infectious diseases and under-nutrition as the major determinants of poor health. Whenever this occurs, Satcher (2001) points out that obesity poses public health and policy concerns due to the associated costs, high prevalence and negative health effects.

Indeed NCDs accounts for $63 \%$ of all deaths worldwide. These diseases were projected as early as 2010 to lead to the loss of over US\$ 47 trillion by 2030. This would be great loss since it is equivalent to $75 \%$ of global GDP of US\$ 63 trillion in 2010 . Such money could reduce the less-than-two-US-dollar-a-day poverty in at least 2.5 billion people for more than 50 years (UN, 2010). As this continues, poor countries such as Kenya are expected to suffer greatly as they commit huge chunks of their national GDP to handling NCDs.

In Kenya about $30 \%$ of adults are overweight while another $9 \%$ are obese. Although, the "WHO Global Action Plan for the Prevention and Control of Non-Communicable Diseases 2013-2020," advocates for the reduction of NCDs by 25\% by 2025, this may not be tenable in Kenya with the high prevalence of overweight and obesity. Furthermore, it may be hard for Kenya to meet "the United Nations political declaration of 2011 on prevention and control non-communicable diseases (NCD)" (WHO, 2011). In this context, it is pertinent to carry out studies aimed at establishing on the factors contributing to NCD in the Kenya. This is of particularly so since there is scanty current data on prevalence of overweight and obesity as priority has always been on undernutrition (Mendez et al., 2005). The main objective of this study was to determine prevalence of overweight and obesity among Kenya Medical Training College staff.

\subsection{METHODOLOGY}

\subsection{Research Site}

The study was undertaken in Kenya Medical Training College (KMTC) Nakuru Campus. The campus has more than 800 students, 18 academic staff and 75 non-teaching staff numbering. It is situated along Crescent Road in Nakuru town, Kenya. Owing to the fact that most of Kenya's health personnel are trained at KMTC campuses, it can be conceptualized that overweight and obesity among members of staff would affect training processes in wake of NCDs among these members of staff. This would go on to adversely affect the health sector in Kenya. It is for this reason that the study focused on KMTC Nakuru Campus. Another reason for targeting the campus is the fact that it is the second largest campus in Kenya and that the researchers live close to it.

\subsection{Methods and research design}

The study adopted the descriptive survey cross sectional design. It involved measurement of height, taking weight and calculation of Body Mass Index (BMI) of all members of staff present during the study period. All members of staff at KMTC Nakuru in the month of March 2016 were purposively recruited for the study. Members of staff were drawn from "department of Clinical Medicine, Nursing, Medical Laboratory Science, Environmental Health Science, Pharmacy, and Physiotherapy." The study variables were: Independent variables -Members of staff, Dependent - Obesity, Intervening Variable (inaccurate measurement of height and taking of weight). The study used a height meter, weighing machine and body mass index wheel was used to collect data. Computer programme Microsoft word was used to type the research document and to generate tables and graphs for data analysis. The data was collected by taking the height and weight of the respondents. The BMI wheel was then used to identify the BMI of the staff members. Several ethical considerations informed the study. These included, getting a research authorization letter from the research committee of KMTC. Consent was also sought from the Principal KMTC Nakuru. The respondents were assured of confidentiality and privacy. In this regard, no identifying information was in the analysis.

\subsection{RESULTS AND DISCUSSION}

In this study, 15 teaching staff members and 74 non-teaching staff members were interviewed. The Body Mass Index (BMI) of the study respondents was sought as shown in Table 1 . 
International Journal of Advances in Scientific Research and Engineering (ijasre), Vol 5 (7), July-2019

Table 1: Results Table

\begin{tabular}{|c|c|c|c|c|c|c|}
\hline \multirow{2}{*}{} & & \multicolumn{4}{c|}{ KMTC NAKURU STAFF MEMBERS } \\
\cline { 3 - 7 } & \multirow{2}{*}{ BMI (kg/m $\left.{ }^{2}\right)$} & BMI & \multicolumn{2}{|c|}{ Teaching Staff } & \multicolumn{2}{c|}{ Non-teaching staff } \\
\hline \multirow{2}{*}{ from } & \multirow{2}{*}{ up to } & Classification & Total & Percentage (\%) & Total & Percentage (\%) \\
\hline & 18.5 & underweight & 0 & 0 & 2 & $3 \%$ \\
\hline 18.5 & 25 & normal weight & 2 & $13 \%$ & 29 & $39 \%$ \\
\hline 25 & 30 & overweight & 9 & $60 \%$ & 23 & $31 \%$ \\
\hline 30 & 35 & class I obesity & 4 & $27 \%$ & 14 & $19 \%$ \\
\hline 35 & 40 & class II obesity & 0 & 0 & 4 & $5 \%$ \\
\hline 40 & & class III obesity & 0 & 0 & 2 & $3 \%$ \\
\hline & & TOTAL & $\mathbf{1 5}$ & $\mathbf{1 0 0}$ & $\mathbf{7 4}$ & $\mathbf{1 0 0}$ \\
\hline
\end{tabular}

Source: Research Data (2016)

The findings obtained are as follows:

(a) Teaching staff: $13 \%$ of the teaching staff had normal BMI, $60 \%$ were overweight and $27 \%$ had class I obesity.

(b) Non-teaching staff: 3\% were underweight, 39\% had normal BMI, 31\% were overweight, $19 \%$ had class I obesity, $5 \%$ had class II obesity and 3\% had class III obesity.

\subsection{CONCLUSION}

$60 \%$ of the teaching staff was overweight and $27 \%$ of the teaching staff was obese while $31 \%$ of the non-teaching staff was overweight and $27 \%$ were obese.

\subsection{RECOMMENDATION}

The study recommends that KMTC Nakuru Campus administration through Head of Department-Clinic should carry out education to all members of staff on the risks of being overweight and obese. KMTC Nakuru management should plan to carry out annual medical check-up for staff and students. The staff who are overweight and those who are obese should carry out more tests e.g. cholesterol profile, blood pressure checks. On its part, the government should put in place mechanisms for enhancing health education on the dangers of obesity and overweight among its citizens.

\section{REFERENCES}

[1] . Haslam, D.W., \& James, W.P. (2005). Obesity. Lancet (Review), 366 (9492), 1197-209.

[2] . Loscalzo, J., Fauci, A.S., Braunwald, E., Dennis, L. K, Hauser, S.L., \& Longo, D.L. (2008). Harrison's principles of internal medicine. McGraw-Hill Medical. ISBN 0-07-146633-9.

[3]. Mendez, M.A., Monteiro, C.A., \& Popkin, B.M. (2005). Overweight exceeds underweight among women in most developing countries, The American Journal of Clinical Nutrition, 81(3), 714-721

[4] . Mohammad, M.Z., Rahman, M., Rahman, R., Bhuiyan, M.R., Karim, N., Chowdhury, A.J. (2016). Prevalence of Risk Factors for Non-Communicable Diseases in Bangladesh: Results from STEPS Survey 2010. Indian J Public Health, 60(1): $17-25$.

[5] . Ogden C.L., Carroll, M.D., Kit, B.K., \& Flegal K. M. (2014). Prevalence of childhood and adult obesity in the United States, 2011-2012. Journal of the American Medical Association, 311(8), 806-814.

[6] . Satcher, D. (2001). The Surgeon General's Call to Action to Prevent and Decrease Overweight and Obesity. U.S. Dept. of Health and Human Services, Public Health Service, Office of Surgeon General.

[7] . WHO. (2000). Obesity: preventing and managing the global epidemic (Report). World Health Organization, 1-2.

[8] . WHO. (2011). Political Declaration - World Health Organization. World Health Organization. Accessed on July 4, 2019 from: https://www.who.int/nmh/events/un_ncd_summit2011/political_declaration_en.pdf

[9] . WHO. (2015). Obesity and overweight Fact sheet $N^{\circ} 311$. Geneva: WHO. 